\title{
Ocean Bottom Proton Magnetometer (Design and Test)
}

\author{
Yoshibumi Tomoda, ${ }^{*}$ Hiromi Fujimoto, ${ }^{*}$ Akinori Uchiyama, ${ }^{*}$ \\ Tomio Emura, ${ }^{* *}$ and Iwao NaKano** \\ *Ocean Research Institute, University of Tokyo, Tokyo, Japan \\ ${ }^{* *}$ Japan Marine Science and Technology Center, \\ Yokosuka, Kanagawa, Japan
}

(Received December 23, 1980)

An ocean bottom proton magnetometer was built and tested at the bottom of the sea. The sensor, preamplifier, preamp-control, and battery are placed at sea floor and are connected to a land station by a single coaxial cable of 3,000 meters. Selection of tuning capacitors, data transmission, and battery charging are carried out through the cable and the device can be operated as if it is at hand.

\section{Introduction}

For the purpose of "tectonomagnetic study" at sea, an ocean bottom proton magnetometer was built and tested. The earth's magnetic total force has been measured by towing a proton magnetometer, but accuracy of ship's position is not high enough for detecting time variation of geomagnetic field at sea. Mooring a proton magnetometer at the surface of the sea by rope and anchor also seems to be difficult for the purpose, because a surface sensor will move within a certain limit depending on the difference between rope length and sea depth.

In the case of the ocean bottom proton magnetometer newly tested, sensor coil, preamplifier, and battery are placed at the ocean bottom. Transmission of signal, control of tuning capacity in the preamplifier, and charging of battery are carried out through a single coaxial cable of $9.5 \mathrm{~mm}$ in outer diameter. The device can easily be operated as if it is at hand.

\section{Principle of Operation}

The ocean bottom proton magnetometer has three operating modes: control mode (mode A), signal transmitting mode (mode B), and battery charging mode (mode C) (Fig. $1)$.

At initial state, the system is in control mode. In this mode (mode A), command signals are sent from a micro-computer to the submersible part in 3 characters in ASCII code by $20 \mathrm{~mA}$ current loop. The preamplifier and its control in the submersible part are electrically isolated by use of a photo coupler. Two kinds of command signals are used. One is "change capacity (C) in preamplifier" and the other is "start". These command 


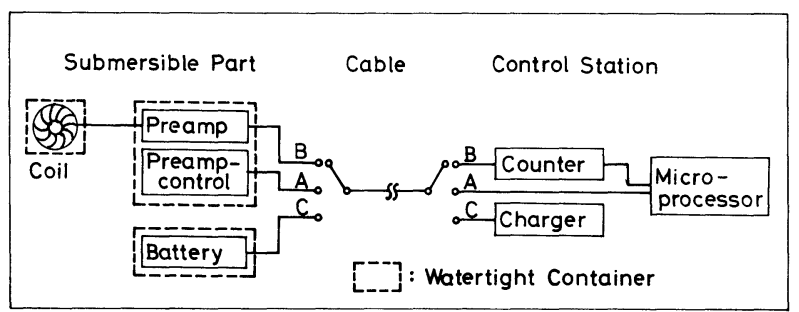

Fig. 1. Ocean bottom proton magnetometer is composed mainly of three parts and has three operating modes: control mode (mode A), signal transmitting mode (mode B), and battery charging mode (mode $\mathrm{C}$ ).

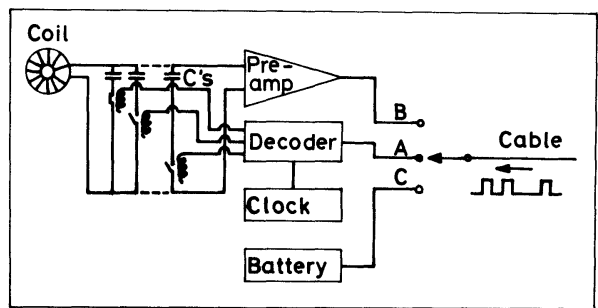

Fig. 2. In mode A, tuning capacitors are selected by decoding serial signal sent from the land station.

signals are decoded by peamp-control, and the value of $\mathrm{C}$ is changed by selecting latch relays connecting capacitors (Fig. 2). The value of $\mathrm{C}$ remains unchanged until the next "change C" command signal is received.

If command signal "start" is sent to the preamp-cotrol, excitation of the sensor coil begins, and mode $\mathrm{A}$ is changed to mode $\mathrm{B}$. This change of mode is carried out synchronously both in preamp-control and in the control station by use of independent crystal clocks.

Ten sec after the "start" signal, mode B is changed to mode C, synchronously by use of clocks as in the change from mode A to mode B. $55 \mathrm{sec}$ after the "start" signal, mode is returned to the initial state (mode A).

\section{Details of the Device}

The ocean bottom proton magnetometer is, as shown in Fig. 1, composed mainly of the following three parts: (1) submersible part, (2) cable connecting the submersible part with the control station, and (3) control station on land or on board a ship.

\subsection{Submersible part}

The submersible part of the proton magnetometer is composed of three parts and is put in watertight containers: a) sensor coil, b) preamplifier and its control, and c) battery for power source.

1,150-turns troidal coil in normal heptane was used as the sensor coil. A low noise 
amplifier of $120 \mathrm{db}$ gain and preamplifier control were made as compactly as possible. The preamplifier control has the following function: i) synchronization between the preampcontrol and the control station, ii) decoding signals from the control station, iii) selection of mode of operation-selection among "control mode", "signal transmitting mode", and "charging mode", and iv) selection of tuning capacitors of the preamplifier.

\subsection{Cable}

A preamplifier, preamp-control and battery are connected to the control station by a coaxial cable of $9.5 \mathrm{~mm}$ in outer diameter. Kevlar was used as tension member in order to be handled easily and its tensile strength is about $400 \mathrm{~kg}$. The cable is nonmagnetic and can be used for connecting the sensor coil with the preamplifier. The cable can also be used when the instrument is towed by a ship with ship's speed slower than 6 knots.

\subsection{Control station}

The control station in the laboratory on land or on board a ship controls the whole system by use of a micro-computer "Apple II". Three sets of proton magnetometers can be operated by a single control station. The micro-computer controls the proton magnetometer and takes in precession signals from the sensor through the preamplifier. The period of signal wave is measured by counters and the results are sent to the microprocessor. The computer calculates geomagnetic total force from the oscillation period of the signal and these outputs are shown through a character display, a digital printer, and an analogue recorder.

\section{Trial Measurement at Sea}

Test of the device was carried out for a week at the bottom $15 \mathrm{~m}$ deep and $200 \mathrm{~m}$ off the Otsuchi Marine Research Center, Ocean Research Institute, University of Tokyo. This place is located in the central part of Sanriku Coast, Tohoku district in Japan.

The sensor coil was floated $3 \mathrm{~m}$ above the sea floor by use of floats. The preamp, control unit, and battery were placed on the sea floor about $50 \mathrm{~m}$ apart from the sensor coil (Fig. 3). Another proton magnetometer was set on land near the control station in the Marine Research Center.

Measurement was successfully carried out from July 4 to July 11, 1980. Results obtained by the ocean bottom magnetometer show short-term fluctuation of several nanno Tesla, because position of the sensor coil is probably fluctuated by sea waves and lateral gradient of geomagnetic field near the sensor is large.

Both results on land and in the sea are given in Fig. 4 which shows overlapping mean of $10 \mathrm{~min}$ for both data. The difference between both results is also shown in the figure. The results show that the geomagnetic daily variation including bay-type storm both on land and at the sea bottom about $200 \mathrm{~m}$ apart each other is nearly the same as expected. It can be said that the ocean bottom magnetometer worked very well.

Detailed comparison of the results obtained at the sea bottom with those on land shows that the amplitude of geomagnetic daily variation at the sea bottom is about $8 \%$ smaller than that measured on land. Fourier transform of land data, sea data, and difference 

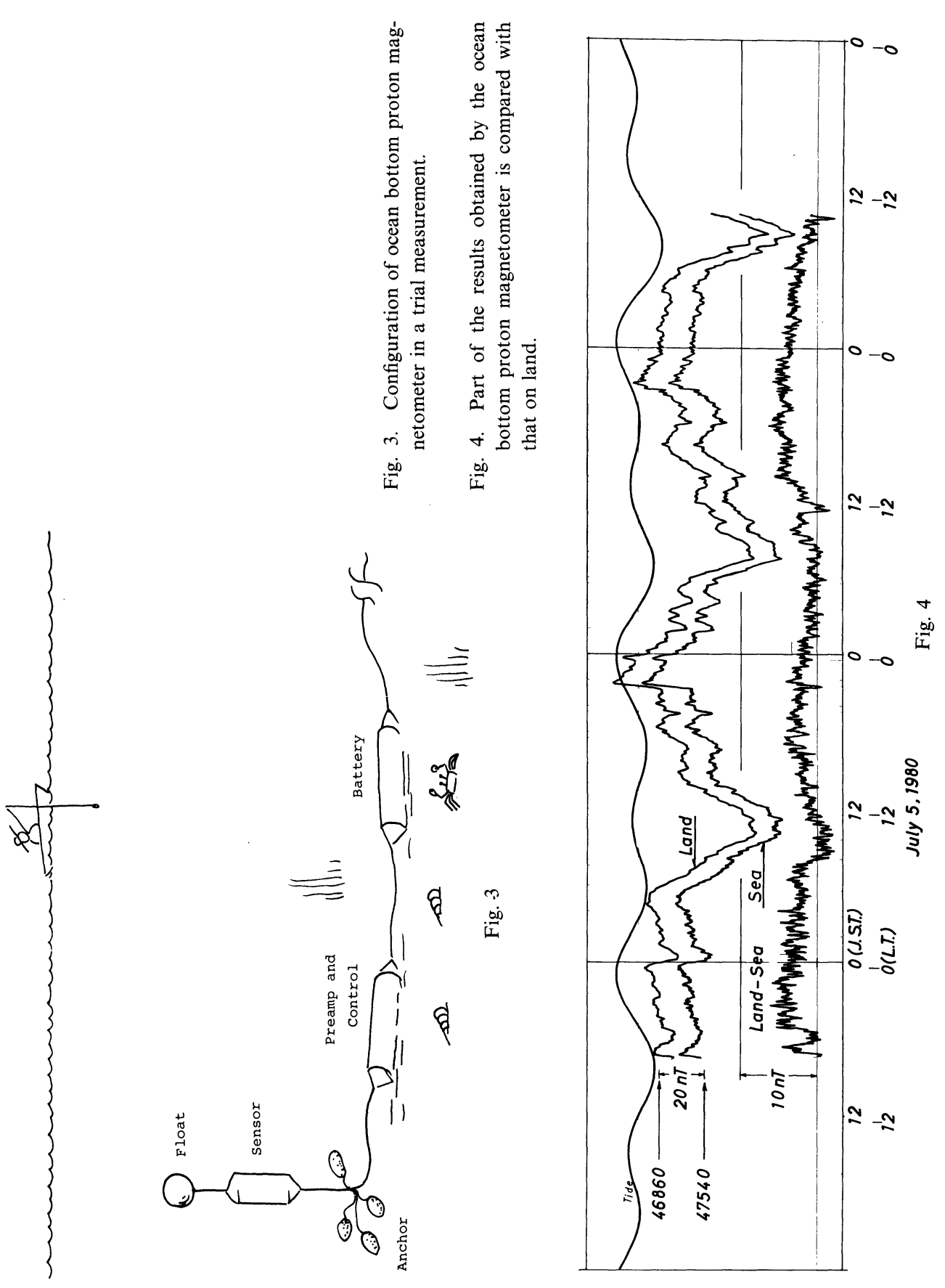


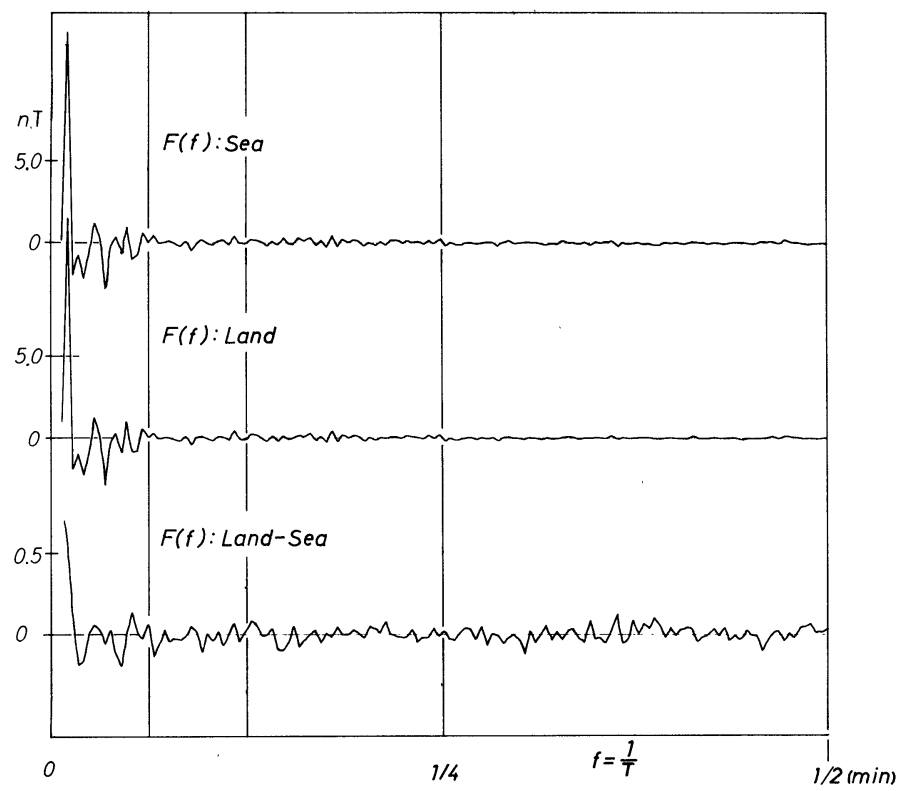

Fig. 5. Fourier transform of the data (land, sea, and land-sea) shows that frequency components other than those of daily variation have little correlation.

between them show that frequency components other than those corresponding to daily variation have little correlation (Fig. 5). The characteristics of these results are similar to those obtained at the coast of Oshima in Izu, but the origin is unknown yet.

The device used in this trial measurement was made by the Science Fund for Promoting Multi-ministerial Projects, Science, and Technology Agency. We owe much to the staff of Otsuchi Marine Center, especially Mr. Shikama, when setting the device in the sea. 